\title{
Melting and Crystallization Process of Polyethylene under High Pressure
}

\author{
Munehisa Yasuniwa \\ Kurume Technical College, Kurume, Fukuoka, Japan. \\ Chitoshi Nakafuku and Tetuo Takemura \\ Department of Applied Science, Faculty of Engineering, \\ Kyushu University, Fukuoka, Japan.
}

(Received August 16, 1972)

\begin{abstract}
Melting and crystallization temperatures of extended- and folded-chain crystals under high pressure are precisely obtained by a microdifferential thermal analysis. In the cooling process from the fused state the crystallizations of extended and folded chains occur successively by two steps. The growth rate of extended-chain crystals is fairly large at the crystallization temperature of the extended chain, and is accelerated by raising pressure. The extended-chain crystal grows directly at its crystallization temperature under high pressure and it does not need long duration to form a complete extended-chain crystal. When the sample is quenched to the crystallization temperature of the folded-chain crystal, the folded-chain lamellae grow for the first time, and gradually thicken into an extended-chain crystal for the reason that the extended chain has a lower free energy than the folded chain under high pressure. These facts are clarified by the use of morphological study.

KEY WORDS Polyethylene / Melting / Crystallization / High Pressure / Differential Thermal Analysis / Morphology /
\end{abstract}

Many authors ${ }^{1-9}$ have studied the formation of extended-chain crystals of polyethylene under high pressure. They are more or less inclined to believe that a long time is necessary for the formation of an extended-chain crystal. We have our doubts about this because the extended chain of poly(tetrafluoroethylene $)^{10}$ or poly(chlorotrifluoroethylene) $^{11}$ crystallizes rather easily.

Some authors ${ }^{4,12,13}$ maintain that folded-chain lamellae are initially formed and thicken under pressure with time into an extended-chain lamellae.

Other authors ${ }^{8,14,16}$ maintain that the direct formation of the extended-chain crystal takes place under high pressure. We believe that both opinions, which are contrary to each other, are correct.

To destroy the believe that a long time is necessary for the formation of an extended-chain crystal and to clarify that both the above views are correct, it is necessary to clarify in detail the process of melting and crystallization of polyethylene under high pressure. A simple method of carrying out this project is a microdifferential thermal analysis under high pressure. In this paper the project is performed by the development of a microthermal analysis under high pressure.

\section{EXPERIMENTAL}

In the thermal measurement under high pressure the use of a sheathed thermocouple is very convenient from the standpoint of sealing techniques. However, the large heat conductivity along the sheathed tube prevents detailed endothermic and exothermic signals. This is one reason why the application of a sealed type sheathed thermocouple ${ }^{3}$ does not present refined data on the melting and crystallization of polyethylene under high pressure. To eliminate this difficulty, the use of an open-type sheathed thermocouple is necessary. In this case, how- 


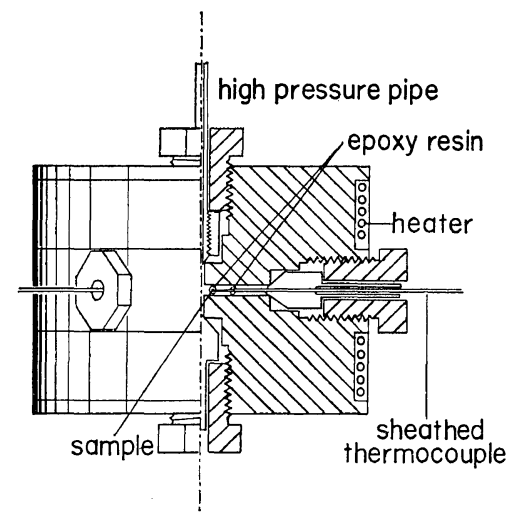

Figure 1. The apparatus for micro differential thermal analysis under high pressure.

ever, a prevention of leakage of transmitting fluids along the filler of the sheathed tube is very important especially under high pressure. This prevention is easily effected by the use of epoxy resin sealing. In this study the sheathed thermocouple of Philips (2ABAc10, diameter $1 \phi$, element diameter $0.14 \phi$ ) was used. About $1 \mathrm{mg}$ of fused polyethylene was stuck to the junction of the chromel-alumel element wire and was covered with a thin film of epoxy resin to keep out the pressure transmitting fluid under high pressure and high temperature.

An apparatus of microdifferential thermal analysis which withstands difficult experiments under thermal stress cycles is shown in Figure 1. Two thermocouple plugs are usually used for the sample and reference, the remainder being kept as a spare or as a preparation cell of the sample for the electron microscope. A light oil is used as a pressure transmitting fluid.

For samples of high-density polyethylene Hizex 2200J $\left(M_{w}=40000\right.$ ) (Mitsui Petrochemical Industries Co.) (sample 1) and Sholex $\left(M_{w}=50000\right)$ (Showa Denko Co.) (sample 2) were used. For the purpose of calibration the fractionated sample $\left(M_{w}=3000, \quad M_{w} / M_{n}=1.02\right) \quad($ sample 4) and the fiber of Hizex (draw ratio 1000\% at $60^{\circ} \mathrm{C}$, about 100 denier) (sample 3) were used. The fiber was wound round the thermocouple and fixed by epoxy resin.

\section{RESULTS AND DISCUSSION}

In the first place, we classify the process of differential thermal analysis into six groups. Run 1 shows the melting curve under high pressure of the sample crystallized at atmospheric pressure (heating rate $6^{\circ} \mathrm{C} / \mathrm{min}$ ). Run

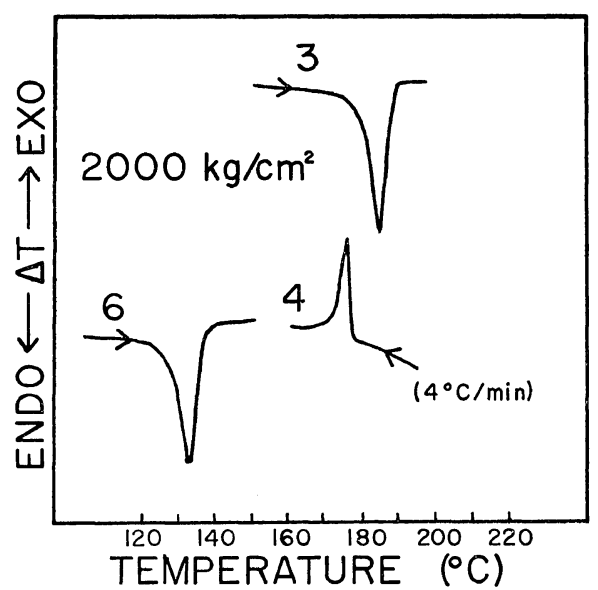

Figure 2. DTA curves of melting and crystallization of sample 1 under $2000 \mathrm{~kg} / \mathrm{cm}^{2}$. Numbers shown in the figure correspond to the experimental conditions described in the text.

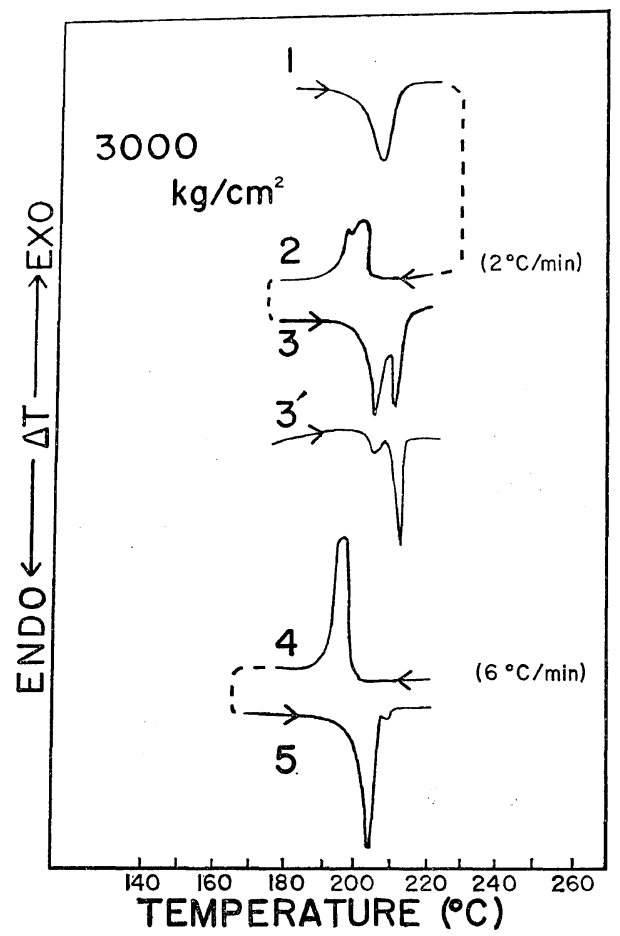

Figure 3. DTA curves of melting and crystallization of sample 1 under $3000 \mathrm{~kg} / \mathrm{cm}^{2}$. 
2 shows the crystallization curve under high pressure by slow cooling (cooling rate is shown in the figure). Run 3 shows the melting curve under high pressure of the sample crystallized under the same high pressure by slow cooling (heating rate $6^{\circ} \mathrm{C} / \mathrm{min}$ ). Run 4 shows the crystallization curve under high pressure by rapid cooling (cooling rate is shown in the figure). Run 5 shows the melting curve under high pressure of the sample crystallized under the same high pressure by rapid cooling (heating rate $6^{\circ} \mathrm{C} /$ min). Run 6 shows the melting curve at atmospheric pressure of the sample crystallized under high pressure (heating rate $6^{\circ} \mathrm{C} / \mathrm{min}$ ).

The melting and crystallization curves of sample 1 are uncomplicated up to about $2500 \mathrm{~kg} /$ $\mathrm{cm}^{2}$ as shown in Figure 2, and show the melting and crystallization of the folded-chain crystal. The crystallization process has no effect on the melting curve. The melting curve at atmospheric pressure of the sample crystallized under high pressure (run 6) is the same as that of the sample crystallized under atmospheric pressure.

Above about $2500 \mathrm{~kg} / \mathrm{cm}^{2}$ the melting and crystallization curves are complicated. Those

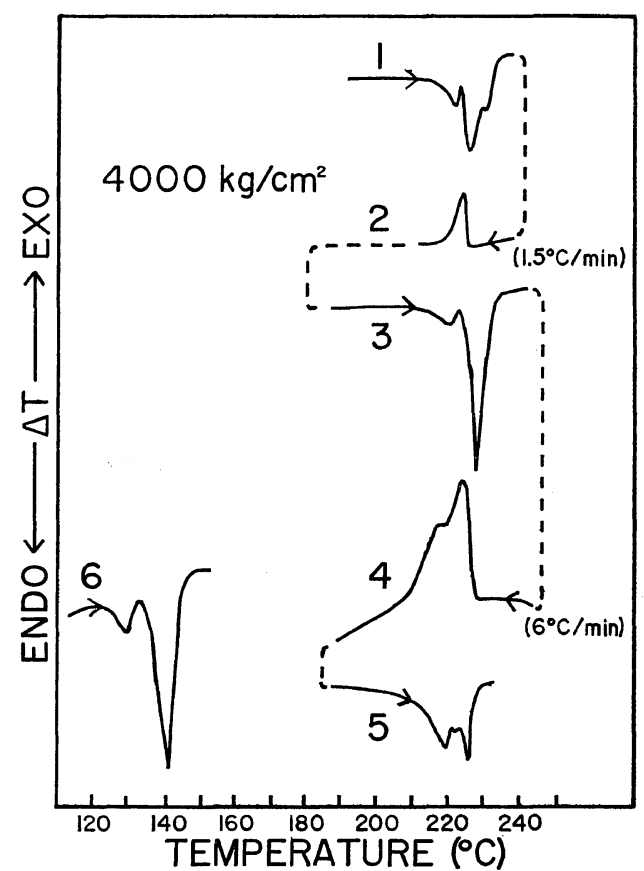

Figure 4. DTA curves of melting and crystallization of sample 1 under $4000 \mathrm{~kg} / \mathrm{cm}^{2}$. under $3000 \mathrm{~kg} / \mathrm{cm}^{2}$ are shown in Figure 3. The melting curve of the sample crystallized at atmospheric pressure (run 1) shows the simple endothermic melting peak of folded-chain crystals. But the crystallization curve by slow cooling (run 2) shows two exothermic crystallization peaks of the extended-chain crystal and foldedchain crystal, respectively. The melting curve of this sample (run 3) shows two endothermic melting peaks of folded- and extended-chain crystals. If the sample is crystallized by slower cooling $\left(0.3^{\circ} \mathrm{C} / \mathrm{min}\right)$, the melting peak of the extended-chain crystal makes remarkable progress (run $3^{\prime}$ ). On the contrary, the sample crystallized by rapid cooling (run 4) shows a remarkable progress of the folded-chain crystal (run 5). The two stepped crystallizations by slow cooling can be observed directly by the use of the optical observation of the diamond anvil apparatus.

The melting and crystallization curves under

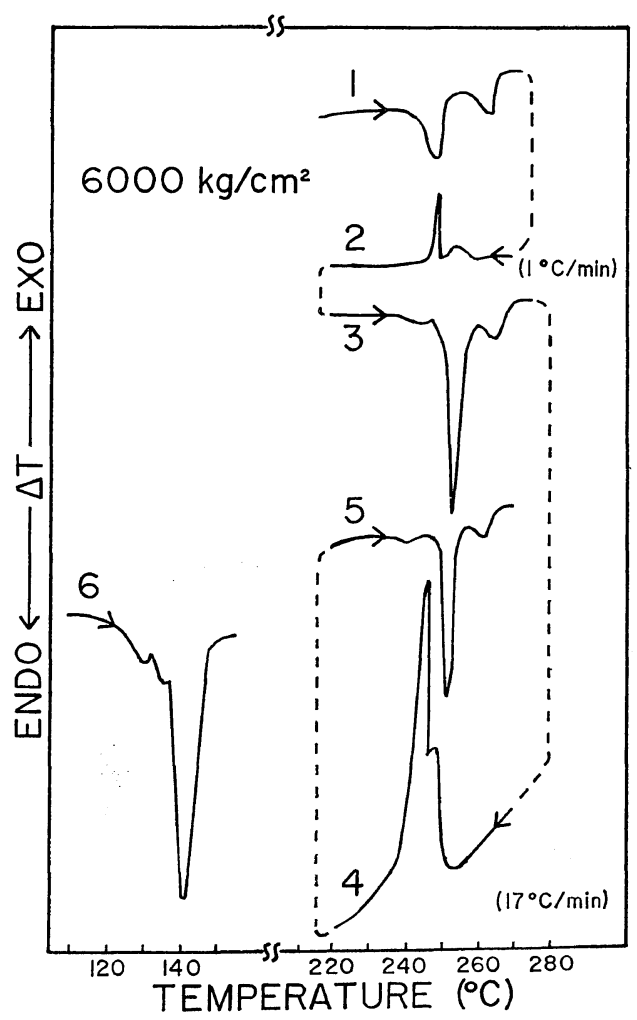

Figure 5. DTA curves of melting and crystallization of sample 1 under $6000 \mathrm{~kg} / \mathrm{cm}^{2}$. 
$4000 \mathrm{~kg} / \mathrm{cm}^{2}$ are shown in Figure 4. The extended-chain crystals play an important role in this case. The melting curve of the sample crystallized under atmospheric pressure (run 1) shows the crystallization into an extended-chain crystal and its melting after the melting of the folded-chain crystal. The crystallization curve under high pressure by slow cooling (cooling rate $1.5^{\circ} \mathrm{C} / \mathrm{min}$ ) (run 2) shows only the crystallization of the extended-chain crystal and does not show clearly that of the folded-chain crystal. The melting curve of the sample crystallized under high pressure by slow cooling (run 3) shows a slight endothermic peak of melting of the folded-chain crystal and a large endothermic melting peak of the extended-chain crystal. The crystallization curve under high pressure by rapid cooling (run 4) shows endothermic crystallization peaks of extended- and foldedchain crystals. The melting curve under high pressure of that sample shows two endothermic peaks of folded- and extended-chain crystals (run 5). The melting curve at atmospheric pressure of the sample crystallized under high pres-

Table I. Melting and crystallization temperature of polyethylene under high pressure Sample 1 (Hizex)

\begin{tabular}{|c|c|c|c|c|c|c|}
\hline \multirow[b]{2}{*}{$\begin{array}{c}\text { Pressure, } \\
\mathrm{kg} / \mathrm{cm}^{2}\end{array}$} & \multicolumn{2}{|c|}{ Folded-chain crystal } & \multicolumn{2}{|c|}{ Extended-chain crystal } & \multicolumn{2}{|c|}{ Unknown structure } \\
\hline & $\begin{array}{c}\text { Melting } \\
\text { temperature, } \\
{ }^{\circ} \mathrm{C}\end{array}$ & $\begin{array}{c}\text { Crystallization } \\
\text { temperature, } \\
{ }^{\circ} \mathrm{C}\end{array}$ & $\begin{array}{c}\text { Melting } \\
\text { temperature, } \\
{ }^{\circ} \mathrm{C}\end{array}$ & $\begin{array}{l}\text { Crystallization } \\
\text { temperature, } \\
{ }^{\circ} \mathrm{C}\end{array}$ & $\begin{array}{l}\text { Melting } \\
\text { temperature, } \\
{ }^{\circ} \mathrm{C}\end{array}$ & $\begin{array}{c}\text { Crystallization } \\
\text { temperature, } \\
{ }^{\circ} \mathrm{C}\end{array}$ \\
\hline 1 & 136 & 120 & & & & \\
\hline 1000 & 162 & 152 & & & & \\
\hline 2000 & 184 & 175 & & & & \\
\hline 3000 & 206 & 198 & 212 & 200 & & \\
\hline 4000 & 219 & & 227 & 223 & 230 & \\
\hline 5000 & 232 & & 241 & 237 & 247 & \\
\hline 6000 & 244 & & 252 & 247 & 259 & 253 \\
\hline
\end{tabular}

Sample 2 (Sholex)

\begin{tabular}{|c|c|c|c|c|c|c|}
\hline \multirow[b]{2}{*}{$\begin{array}{c}\text { Pressure, } \\
\mathrm{kg} / \mathrm{cm}^{2}\end{array}$} & \multicolumn{2}{|c|}{ Folded-chain crystal } & \multicolumn{2}{|c|}{ Extended-chain crystal } & \multicolumn{2}{|c|}{ Unknown structure } \\
\hline & $\begin{array}{c}\text { Melting } \\
\text { temperature, } \\
{ }^{\circ} \mathrm{C}\end{array}$ & $\begin{array}{c}\text { Crystallization } \\
\text { temperature, } \\
{ }^{\circ} \mathrm{C}\end{array}$ & $\begin{array}{c}\text { Melting } \\
\text { temperature, } \\
{ }^{\circ} \mathrm{C}\end{array}$ & $\begin{array}{c}\text { Crystallization } \\
\text { temperature, } \\
{ }^{\circ} \mathrm{C}\end{array}$ & $\begin{array}{c}\text { Melting } \\
\text { temperature, } \\
{ }^{\circ} \mathrm{C}\end{array}$ & $\begin{array}{c}\text { Crystallization } \\
\text { temperature, } \\
{ }^{\circ} \mathrm{C}\end{array}$ \\
\hline 1 & 128 & 117 & & & & \\
\hline 1000 & 157 & 145 & & & & \\
\hline 2000 & 179 & 166 & & & & \\
\hline 3000 & 206 & 198 & 213 & 201 & & \\
\hline 4000 & 220 & & 226 & 218 & 228 & \\
\hline 5000 & 231 & & 238 & 233 & 245 & \\
\hline 6000 & 249 & & 252 & 248 & 262 & \\
\hline
\end{tabular}

Sample 3 (fixed fiber)

\begin{tabular}{cc}
$\begin{array}{r}\text { Pressure, } \\
\mathrm{kg} / \mathrm{cm}^{2}\end{array}$ & $\begin{array}{c}\text { Melting temperature, } \\
{ }^{\circ} \mathrm{C}\end{array}$ \\
\hline 1 & 135 \\
1000 & 164 \\
2000 & 190 \\
3000 & 212 \\
4000 & 230 \\
5000 & 245 \\
6000 & 254 \\
\hline
\end{tabular}

Sample 4 (fractionated polyethylene, $\boldsymbol{M}_{w}=3000$ )

\begin{tabular}{rcc}
\hline $\begin{array}{c}\text { Pressure, } \\
\mathrm{kg} / \mathrm{cm}^{2}\end{array}$ & $\begin{array}{c}\text { Melting } \\
\text { temperature, }\end{array}{ }^{\circ} \mathrm{C}$ & $\begin{array}{c}\text { Crystallization } \\
\text { temperature, }{ }^{\circ} \mathrm{C}\end{array}$ \\
\hline 1 & 127 & 120 \\
2000 & 182 & 171 \\
4000 & 220 & 207 \\
6000 & 249 & 234 \\
\hline
\end{tabular}


sure by slow cooling (run 6) shows two endothermic peaks of folded- and extended-chain crystals.

The melting and crystallization curves under $6000 \mathrm{~kg} / \mathrm{cm}^{2}$ are shown in Figure 5. The melting curve of the sample crystallized at atmospheric pressure (run 1) shows gradual recrystallization into an extended-chain crystal and its melting. After these processes the melting curve shows recrystallization into an unknown structure and its melting. The crystallization curve under high pressure by slow cooling (run 2) shows endothermic crystallization peaks of an unknown structure and an extended-chain crystal. The melting curve under high pressure of the sample (run 3) shows a small melting peak of a foldedchain crystal, a large melting peak of an extended-chain crystal and a melting peak of an unknown structure. If the sample is crystallized by rapid cooling (run 4), the crystallization curve does not show the crystallization peak of the folded-chain crystal. The melting curve of that sample (run 5) shows the same feature as that of run 3. The melting curve at atmospheric pressure of the sample crystallized under high pressure by slow cooling (run 6) shows the same features as those mentioned by authors. ${ }^{6,7,15}$ The melting and crystallization temperatures of each crystalline form are summarized in Table I. The features of melting and crystallization of sample 2 are the same as those of sample 1, and the temperatures are coincident with those of sample 1 as shown in Table I.

The melting and crystallization temperatures of the folded-chain crystal, the extended-chain crystal and other structures in these experiments are not thermodynamic quantities, for the structure of the sample changes step by step during the interval of heating and cooling processes. To show that these quantities are almost coincident with those of the thermodynamic quantities, it is necessary to study the melting and crystallization curves of the samples of fixed crystalline structure. Sample 4 (chain length 270A) was used as a model of a sample of fixed folded-chain length, though it does not fold but extend. The melting and crystallization temperatures of sample 4 are shown in Table I. The melting and crystallization temperatures of

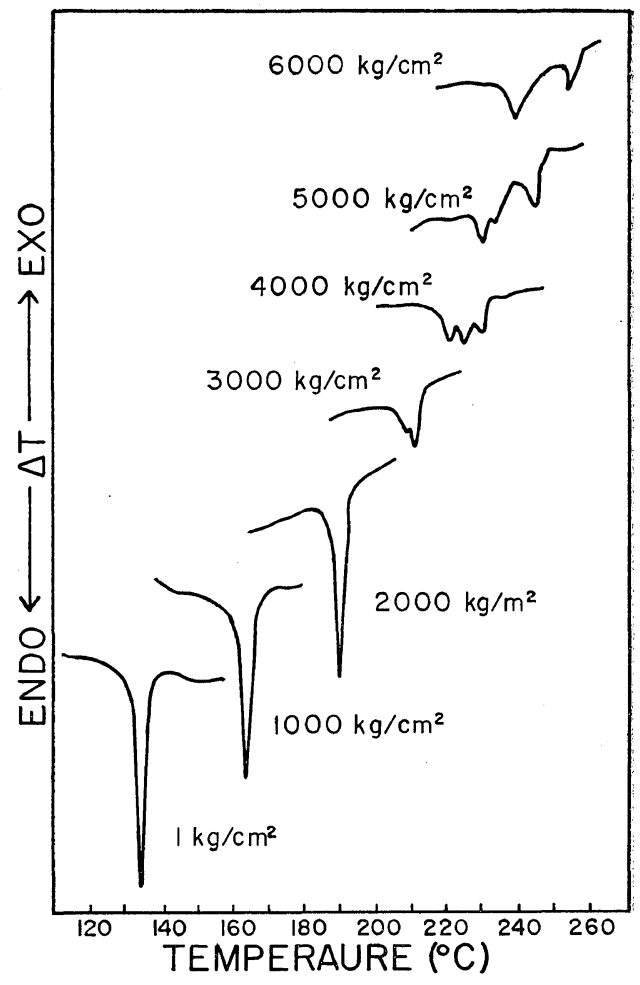

Figure 6. DTA curves of melting of the sample: of fixed fiber under high pressure.

this sample are coincident with those of samples 1 and 2. Sample 3 (fixed fiber) was used as a model of a sample of fixed extended-chain length. The melting temperature of this sample 3 (the upper endothermic peak of each run correspond to the melting temperature of well aligned fiber) is coincident with those of samples 1 and 2 as shown in Figure 6 and Table I.

The melting and crystallization temperatures of sample 1 are compared with those of Wunder$\operatorname{lich}^{3}$ as shown in Figure 7. The difference between this data and Wunderlich's about the melting temperature of the folded-chain crystal is very large. We can not explain this difference. Some crystallization conditions of extended-chain crystal formation by other authors ${ }^{1,2}$ are shown in Figure 7. These crystallization conditions are lower than our crystallization temperature of the extended-chain crystal. This is the reason why they need a long time to crystallize their sample into an extended-chain crystal. If the sample is crystallized at our crystallization tem- 


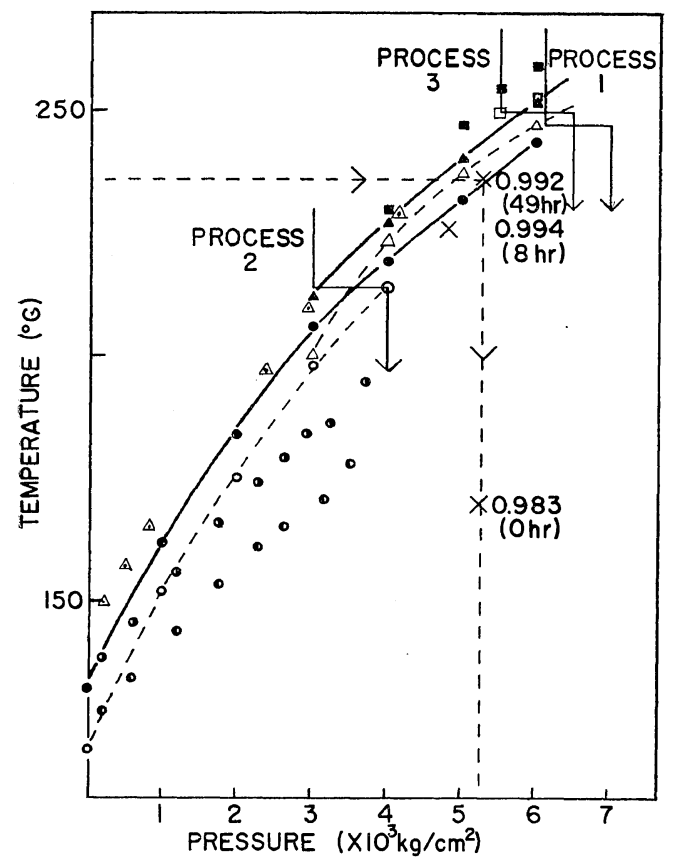

Figure 7. Melting and crystallization temperatures $v s$. pressure: $\bullet$, melting temperature of the foldedchain crystal; $\bigcirc$, crystallization temperature of the folded-chain crystal; $\Delta$, melting temperature of the extended-chain crystal; $\triangle$, crystallization temperature of the extended-chain crystal; and melting and crystallization temperatures of the folded-chain crystal after Wunderlich; $\Delta$, melting temperature of the extended-chain crystallized under $5000 \mathrm{~kg} / \mathrm{cm}^{2}$ obtained by Davidson and Wunderlich; $\times$, crystallization conditions obtained by Arakawa and Wunderlich; and $\square$, melting and crystallization temperatures of unknown structure. Broken line and arrow show the process and the obtained density is shown in the figure. Process 1, 2, and 3 are described in the text.

perature of the extended-chain crystal, the sample rapidly crystallizes. Figure 8 shows the morphological structure of a sample crystallized for $10 \mathrm{~min}$ at the crystallization temperature of extended-chain crystals $\left(223^{\circ} \mathrm{C}\right)$ under $4000 \mathrm{~kg} / \mathrm{cm}^{2}$. The structure of the extended-chain crystal has taken considerable growth. The growth rate of the extended-chain crystal is accelerated by pressure. Figure 9 shows the morphological structure of a sample crystallized for $20 \mathrm{~min}$ at the crystallization temperature of extended-chain crystals $\left(247^{\circ} \mathrm{C}\right)$ under $6000 \mathrm{~kg} / \mathrm{cm}^{2}$. The struc-

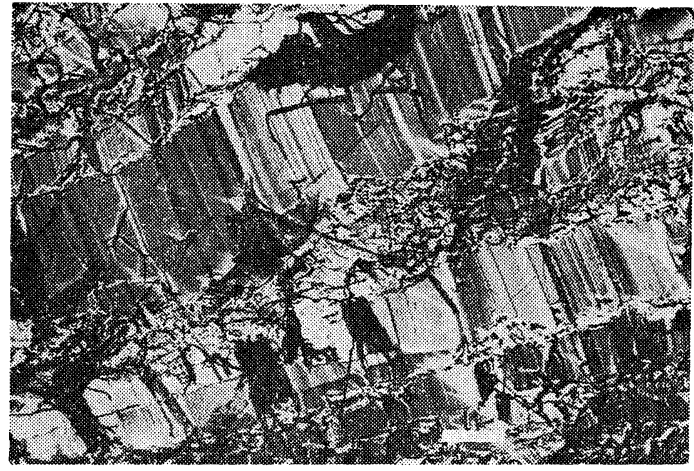

Figure 8. Fracture surface of sample 1 crystallized for $10 \mathrm{~min}$ under $4000 \mathrm{~kg} / \mathrm{cm}^{2}$ at $223^{\circ} \mathrm{C}$. The scale bar on this and subsequent micrograph represents $1 \mu$.

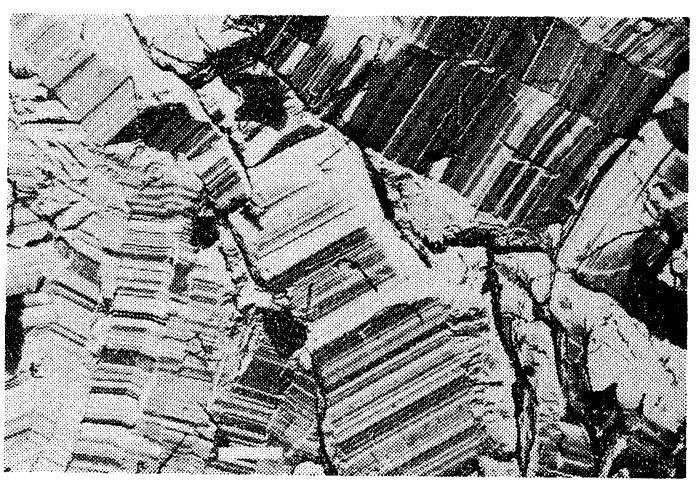

Figure 9. Fracture surface of sample 1 crystallized for $20 \mathrm{~min}$ under $6000 \mathrm{~kg} / \mathrm{cm}^{2}$ at $247^{\circ} \mathrm{C}$. The density of this sample measured by the gradient column method is 0.994 .

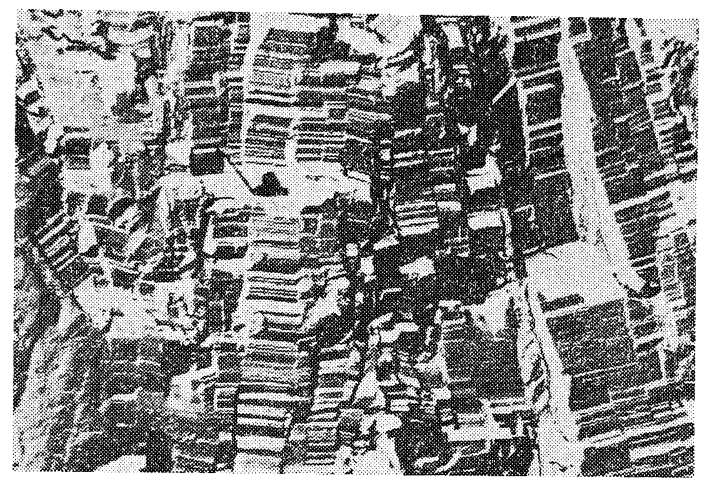

Figure 10. Fracture surface of sample 1 passed through process 1 . This figure shows the direct formation of the extended-chain crystal. 
ture of the extended-chain crystal has taken complete growth. The density of this sample measured by the gradient column method is 0.994. This density correspond to the maximum value obtained by Wunderlich as shown in Figure 7.

If the sample of fused state under $6000 \mathrm{~kg} /$ $\mathrm{cm}^{2}$ is crystallized at the crystallization temperature of the extended-chain crystal $\left(247^{\circ} \mathrm{C}\right)$ for $5 \mathrm{~min}$ and is quenched rapidly by raising the pressure to $7000 \mathrm{~kg} / \mathrm{cm}^{2}\left(1000 \mathrm{~kg} / \mathrm{cm}^{2} / 2 \mathrm{sec}\right.$ ) (process 1), the sample takes an extended-chain structure as shown in Figure 10. This fact shows the direct formation of the extended-chain crystal

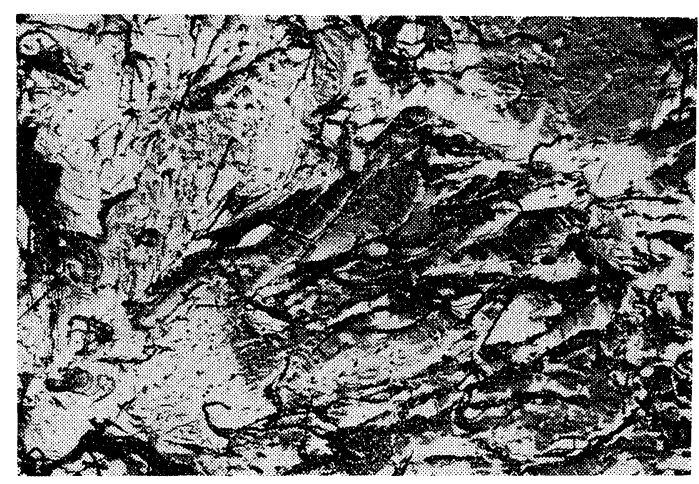

Figure 11. Fracture surface of sample 1 passed through process 2 . The holding time at the crystallization temperature of the folded-chain crystal $\left(214^{\circ} \mathrm{C}, 4000 \mathrm{~kg} / \mathrm{cm}^{2}\right)$ is $5 \mathrm{~min}$. Folded-chain crystals can be seen in the figure.

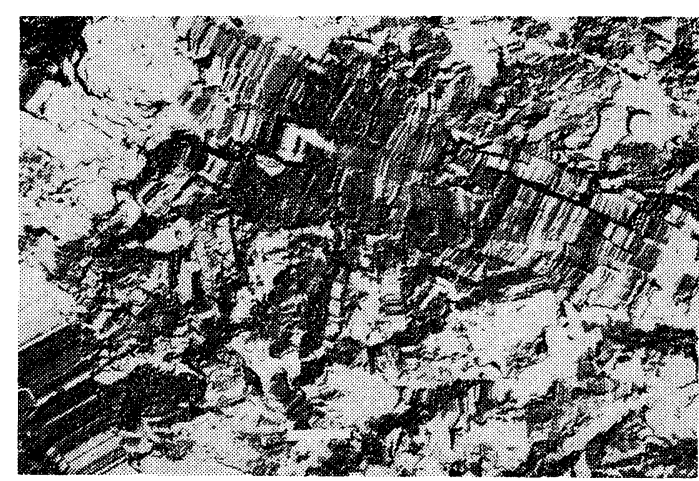

Figure 12. Fracture surface of sample 1 passed through process 2 . The holding time at the crystallization temperature of the folded-chain crystal $\left(214^{\circ} \mathrm{C}, 4000 \mathrm{~kg} / \mathrm{cm}^{2}\right)$ is $5 \mathrm{hr}$. Folded-chain crystals are thickened into extended-chain crystals as shown in the figure. at this crystallization temperature.

If a sample of the fused state $\left(214^{\circ} \mathrm{C}, 3000\right.$ $\mathrm{kg} / \mathrm{cm}^{2}$ ) is quickly brought to the second state of folded-chain crystallization temperature $\left(214^{\circ} \mathrm{C}\right.$, $4000 \mathrm{~kg} / \mathrm{cm}^{2}$ ) for $5 \mathrm{~min}$, the morphological structure of this sample takes on a folded-chain crystal structure as shown in Figure 11 (process 2). If the holding time in this second state is sufficiently long $(5 \mathrm{hr})$, the folded-chain crystal is thickened into an extended-chain crystal as shown in Figure 12. These features correspond to the DTA diagram as shown in Figure 13. In this second state the growth rate of the folded-chain crystal is large compared with the growth rate of the extended-chain crystal. Therefore, the

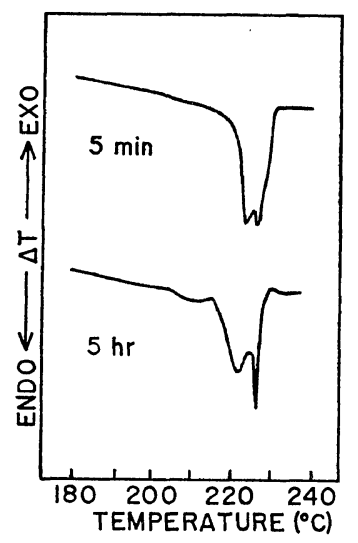

Figure 13. DTA curves of the sample passed through the processes of Figures 11 and 12. If the holding time in this second state is sufficiently long, the endothermic peak of the extended-chain crystal shows remakable progress.

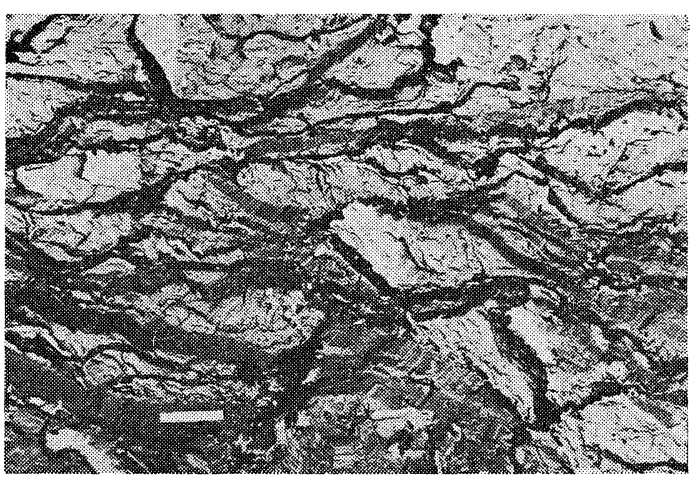

Figure 14. Fracture surface of sample 1 passed through the process 3 . 
formation of the folded-chain crystal takes place at first. However, the extended-chain crystal has a lower free energy than the folded-chain crystal in this state. Therefore a gradual formation of the extended-chain crystal from the folded-chain crystal takes place as shown in Figure 12.

To study the unknown melting and crystallization peaks which appear under above $4000 \mathrm{~kg} / \mathrm{cm}^{2}$ in DTA curves, a sample of the fused state is crystallized at the crystallization temperature of the unknown structure under $5500 \mathrm{~kg} / \mathrm{cm}^{2}\left(250^{\circ} \mathrm{C}\right)$ for $5 \mathrm{~min}$ and quenched quickly by raising pressure to $6500 \mathrm{~kg} / \mathrm{cm}^{2}$ (process 3). The morphology of this sample does not have a clear structure compared with that of Figure 10 as shown in Figure 14. The optical observation of these melting and crystallization processes by diamond anvils also cannot detect any structural change during melting and crystallization of this unknown structure. It may be a nematic liquidcrystal phase appearing under high pressure, but we have no proof about it.

Acknowledgment. The authors wish to thank Prof. K. Takamizawa of this department for supplying of the fractionated sample $\left(M_{w}=3000\right)$ and for his kind discussion. This work is supported in part by the Takeda Science Foundation.

\section{REFERENCES}

1. B. Wunderlich and T. Arakawa, J. Polym. Sci. Part A, 2, 3697 (1964).

2. P. H. Geil, F. R. Anderson, B. Wunderlich, and T. Arakawa, ibid., Part A, 2, 3707 (1964).

3. T. Davidson and B. Wunderlich, ibid., Part A-2, 7, 377 (1969).

4. B. Wunderlich and T. Davidson, ibid., Part A-2, 7, 2043 (1969).

5. T. Davidson and B. Wunderlich, ibid., Part A-2, 7, 2051 (1969).

6. R. B. Prime, B. Wunderlich, and L. Mellillo, ibid., Part A-2, 7, 2091 (1969).

7. C. L. Gruner, B. Wunderlich, and R. C. Bopp, ibid., Part A-2, 7, 2099 (1969).

8. P. D. Calvert and D. R. Uhlmann, ibid., Part C., 8, 165 (1970).

9. T. Hatakeyama, T. Hashimoto, T. Ishida, M. Ohkuma, M. Kotani, and H. Kanetsuna, Rep. Progr. Polym. Phys. Japan, 14, 199 (1971).

10. C. W. Bunn, A. J. Cobbold, and R. P. Palmer, J. Polym. Sci., 28, 365 (1958).

11. Y. Miyamoto, C. Nakafuku, and T. Takemura, Polymer J., 3, 122 (1972).

12. D. V. Rees and D. C. Bassett, Nature, 219, 368 (1968).

13. D. V. Rees and D. C. Bassett, J. Polym. Sci., Part C., 7, 273 (1969).

14. K. Kato, T. Nose, and T. Hata, Rep. Polym. Phys. Phys. Japan, 14, 187 (1971).

15. J. L. Kardos, Ph. D. Thesis, Case Institute of Technology, Cleveland, (1965).

16. J. L. Kardos, H. M. Li, and K. A. Huckshold, J. Polym. Sci., Part A-2, 9, 2061 (1971). 